XXX. Kongress der Schweizerischen Gesellschaft für Dermatologie und Venereologie vom 9. und 10. Oktober 1948 in Basel

Dermatologica. 1949;98:256

\title{
Sur les antigènes du penicillium notatum
}

H.

Isler

Genève, Travail de la clinique dermatologique universitaire de Genève Directeur: Prof. Dr. W. Jadassohn

De cultures de Penicillium notatum sur milieu synthétique, un produit correspondant à la trichophytine sèche de Bloch, Labouchère et Schaaf a été isolé. Ce produit contient probablement des poly-saccharides azotes. II ne présente aucune activité antistaphylo-coccique. Les experiences faites selon la méthode de Schultz-Dale ont montré: $1^{\circ}$ que ce produit est un antigène; $2^{\circ}$ que les uterus des cobayes sensibilisés par ce produit ne réagissaient pas à la trichophytine sèche isolé d'une culture d'Achorion quinckeanum; $3^{\circ}$ que les uterus des cobayes sensibilisés avec la trichophytine sèche de $\Gamma$ Achorion quinckeanum réagissaient au produit isolé de la culture de Penicillium notatum; que le P. notatum et VA. quinckeanum pro-duísaíent done un ou plusieurs antigènes communs; $4^{\circ}$ que les uterus des cobayes sensibilisés par les produits isolés des cultures de $\mathrm{P}$. notatum et $\mathrm{d}$ 'A. quinckeanum ne réagissaient ni à la pénicilline $\mathrm{G}$ cristalHsée, ni à la streptomycine.

(A paru in extenso dans Acta allergologica I, 297, 1948.) 